Www.jmscr.igmpublication.org

Impact Factor (SJIF): 6.379

Index Copernicus Value: 79.54

ISSN (e)-2347-176x ISSN (p) 2455-0450

crossrefDOI: https://dx.doi.org/10.18535/jmscr/v6i10.165

Journal Of Medical Science And Clinical Research

IGM Publication

An Official Publication of IGM Publication

\title{
Study of NT-Pro BNP in Acute Coronary Syndromes
}

Authors

\section{Dr G. Sivachandran ${ }^{1}$, Prof Dr M. Senthilvelan ${ }^{2}$, Dr K. Baburaj ${ }^{3}$, Dr A. Elaiyaraja ${ }^{4}$, Dr Jayaram Kosalram ${ }^{5}$, Dr G. Arul Venkadesh}

${ }^{1}$ Post Graduate, Department of General Medicine, Rajah Muthiah Medical College, Annamalai University, Chidambaram, Tamilnadu

${ }^{2}$ Professor \& HOD, Department of General Medicine, Rajah Muthiah Medical College, Annamalai University, Chidambaram, Tamilnadu

${ }^{3}$ Reader, Department of General Medicine, Rajah Muthiah Medical College, Annamalai University, Chidambaram, Tamilnadu

${ }^{4,5}$ Senior Resident, Department of General Medicine, Rajah Muthiah Medical College, Annamalai University, Chidambaram, Tamilnadu

${ }^{6}$ Post Graduate, Department of General Medicine, Rajah Muthiah Medical College, Annamalai University, Chidambaram, Tamilnadu Corresponding Author

Prof Dr M. Senthilvelan

Professor \& HOD, Department of General Medicine, Rajah Muthiah Medical College, Annamalai University, Chidambaram, Tamilnadu, India.

Email:profmsv@hotmail.com

\begin{abstract}
Background: Acute Coronary Syndrome is one of the commonly diagnosed life threatening condition as of now. Hence it is necessary to diagnose early and assess the severity of disease as soon as possible. This study is done to prove the correlation of cardiac marker NT-pro BNP in Acute Coronary Syndrome.

Aim: To estimate the serum level of $N$-terminal pro-Brain natriuretic peptide levels in Acute coronary syndrome and its relationship between STEMI, NSTEMI and Unstable angina patients. Also to find the association for levels of NTpro-BNP in patients with acute coronary syndrome and ejection fraction.

Materials and Methods: 40 patients of age group between 30 to 60 of both sexes who got admitted within 12 hours after onset of symptoms and diagnosed as Acute Coronary Syndrome (STEMI, NSTEMI \& Unstable Angina) in Rajah Muthiah Medical College \& Hospital at Chidambaram, Tamilnadu during the period of November 2016 to August 2018) without heart failure ( $\geq$ Killip class II were excluded) and chronic kidney disease were taken for the present study. The levels of NT-Pro BNP were measure in blood with Rapid NT-Pro BNP Assay kit.

Results: The mean age of the patient was 49-10+7.45 years \& majority were males (around 60\%). Among ACS NTpro BNP was higher (>100) in most of the patients $(85 \%)$ patients in the study. Here in this study majority patients was STEMI (57.5\%) followed by NSTEMI (25\%) \& Unstable Angina (7\%). The majority of patients with low Ejection Fraction had greater NT pro BNP $(N=4,66.7 \%)$ and majority of normal Ejection Fraction $(N=5,62.5 \%)$ had lower NT pro $B N P(<100)$ which was statistically significant.

Conclusion: NT-pro BNP is reliable biomarker in diagnosing not only STEMI \& NSTEMI but also in unstable angina. NT-pro BNP is high in STEMI compared to NSTEMI \& UA. Levels of NT-pro BNP is significantly had inverse proportion to Ejection Fraction. Low NT-proBNP levels at the time of admission rule out high-risk patients and patients with heart failure.

Keywords: Acute Coronary Syndromes, STEMI, NSTEMI, Unstable Angina, NT-pro BNP, cardiac markers.
\end{abstract}




\section{Introduction}

According to the World Health Organization (WHO), cardiovascular diseases are the leading cause of deaths globally. ${ }^{[1]}$ Cardiovascular diseases involve the blood vessels, the heart, or both of which coronary artery disease is one of the life threatening condition. Patients with coronary artery disease consists of two major groups which includes chronic coronary artery disease (CAD) and acute coronary syndromes (ACS). ${ }^{[2]}$ Acute coronary syndromes caused by sudden blockage of a coronary artery. According to degree and location of blockage it ranges from unstable angina to non-ST-segment elevation myocardial infarction (NSTEMI), ST-segment elevation myocardial infarction (STEMI), and sudden cardiac death. ${ }^{[2]}$

Diagnosis of ACS can be done by strategy which includes proper detailed history, thorough physical examination, electrocardiogram, cardiac biomarkers and imaging studies of heart. ${ }^{[3]}$ Diagnostic Guidelines for ACS includes ECG changes based on Marriotts Criteria, ST segment is elevated by $1 \mathrm{~mm}$ or more in Two or more limb leads or precordial leads $\mathrm{V}_{4}$ to $\mathrm{V}_{6}$ or by $2 \mathrm{~mm}$ or more in two or more precordial leads $\mathrm{V}_{1}$ to $\mathrm{V}_{3}$; or ST segment depressed by $1 \mathrm{~mm}$ or more in two or more precordial leads $\mathrm{V}_{1}$ to $\mathrm{V}_{3} \cdot{ }^{[4]}$ In ECG of STEMI, there may be J-point elevation, hyperacute $\mathrm{T}$ waves, ST-segment elevation and reciprocal-lead ST-segment depression can occur, where as in NSTEMI and unstable angina ECG changes can be normal or ST segment depression / $\mathrm{T}$ wave inversion. ${ }^{[5]}$ The diagnosis of ACS depends on the levels of Serum cardiac markers which commonly includes Creatine kinase (CK), CKMB, Troponin I \& Troponin T, BNP (Brain Natriuretic Peptide), NT Pro-BNP and C-Reactive protein (CRP). ${ }^{[6,7,8,9]}$

The levels of Serum cardiac markers gets elevated during myocardial necrosis i.e., in ACS. B-type natriuretic peptide (BNP), cardiac neurohormone, and its N-terminal fragment (NT-proBNP) are synthesised and secreted from the ventricular myocardium. It is well known that stimulus for their release is the increase in left ventricular wall stress. ${ }^{[10,11]}$ The recent clinical studies have shown that quantity of raise in BNP or NT- Pro BNP can be used to predict the morbidity and mortality in acute coronary syndrome. ${ }^{[12,13]}$

Here in our study the $\mathrm{N}$ - Terminal pro Brain Natriuretic Peptide (NT-proBNP) which is an inactive remnant of a hormonally active Brain Natriuretic peptide (BNP) is measured to predict the severity of STEMI, NSTEMI and unstable angina. This study also intends to see whether the level of NT-ProBNP taken during an event of an ACS, correlates with Age, Sex, Ejection Fraction between STEMI, NSTEMI and unstable angina. Together with these results we provide the evidence that cardiac marker NT-proBNP is independent marker for both diagnosis and also for prognosis in patients with acute coronary syndrome.

\section{Aims and Objectives}

To estimate the serum level of $\mathrm{N}$-terminal proBrain natriuretic peptide levels in Acute coronary syndrome and its relationship between STEMI, NSTEMI and Unstable angina patients. Also to find the association for levels of NT-pro-BNP in patients with acute coronary syndrome and ejection fraction.

\section{Materials and Methodology}

This study is conducted among 40 patients of age group between 30 to 60 of both sexes who got admitted within 12 hours after onset of symptoms and diagnosed as Acute Coronary Syndrome (STEMI, NSTEMI \& Unstable Angina) in Rajah Muthiah Medical College \& Hospital, Annamalai University during the period of November 2016 to August 2018 ) without heart failure ( $\geq$ Killip class II were excluded) and chronic kidney disease. Laboratory Investigations includes blood urea serum creatinine to rule out frank renal failure. Other investigations includes serial ECG monitoring, Echocardiography, blood levels of Troponin T, CK-MB were done. Within 12 hours of the onset of symptoms, the levels of NT-Pro 
BNP were measure in blood with Rapid NT-Pro BNP Assay kit.

Description of the NT proBNP Rapid Assay Kit:

The strips are coated with canine antibodies to human NT pro terminal end of brain Natriuretic peptide. It is a semi quantitative assay and it gives the measurement as $<100 \mathrm{pg} / \mathrm{ml}, 100-500 \mathrm{pg} / \mathrm{ml}$ and $>500 \mathrm{pg} / \mathrm{ml}$. Values below $100 \mathrm{pg} / \mathrm{ml}$ was considered as minimal or insignificant and values above $100 \mathrm{pg} / \mathrm{ml}$ considered significant. Significant values in the range of $100-500 \mathrm{pg} / \mathrm{ml}$ is taken as moderately elevated and values above $500 \mathrm{pg} / \mathrm{ml}$ were taken as moderately elevated.

\section{Observation and Results}

In the present work, the NT pro BNP values of acute coronary syndrome is analysed. A total of
40 patients with acute coronary syndrome is selected. The overall NT pro BNP was analysed by frequency distribution using class intervals. The association of NT pro BNP with types of MI, LV function, age and gender is analysed by Chisquare test of association. The relationship of NTpro BNP with TIMS score is analysed by Spearmanns correlation coefficients. The entire statistical procedure is carried out by statistical packages of social sciences (spss-21).

\section{Age Distribution}

The common age of the patients was 51 to 60 years (50\%). In the age group 41 to 50 years, $30 \%$ was observed. In the age category 31 to 40 years, $20 \%$ was observed. The mean age was $49.10 \pm 7.45$ years.

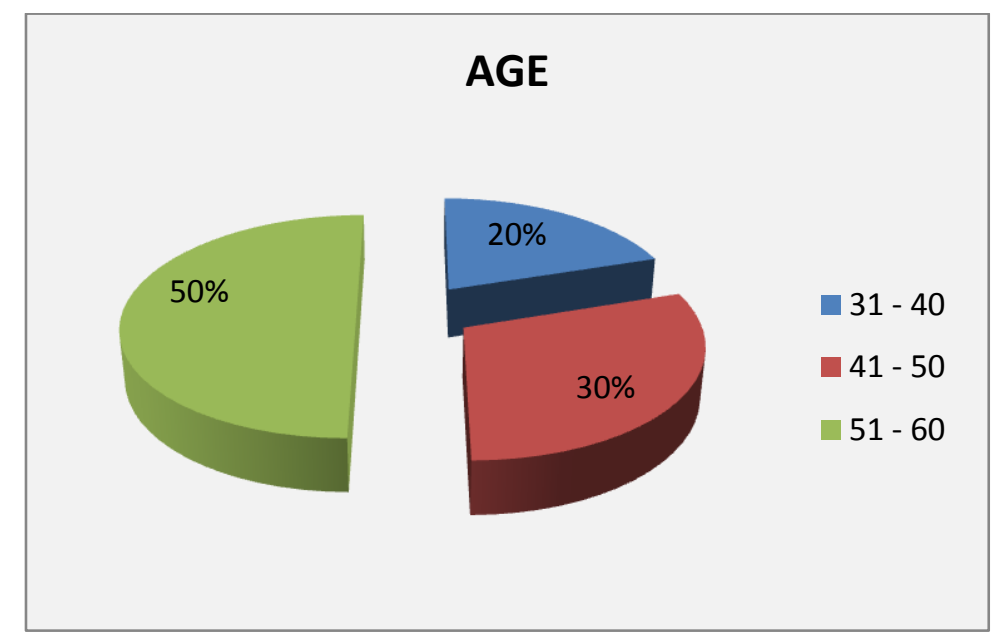

Association of Age with NT pro BNP

\begin{tabular}{|c|c|c|c|c|c|c|c|c|c|}
\hline \multirow{3}{*}{ Age } & \multicolumn{6}{|c|}{ NT Pro BNP } & \multirow{3}{*}{ Total } & \multicolumn{2}{|c|}{ Chi-square Test } \\
\hline & \multicolumn{2}{|c|}{$<100$} & \multicolumn{2}{|c|}{$100-500$} & \multicolumn{2}{|c|}{$>500$} & & & 6 \\
\hline & $\mathbf{N}$ & $\%$ & $\mathbf{N}$ & $\%$ & $\mathbf{N}$ & $\%$ & & Value & $\mathbf{P}^{\prime}$ \\
\hline $30-40$ & - & - & 5 & 62.5 & 3 & 37.5 & 8 & \multirow{4}{*}{8.05} & \multirow{4}{*}{.09} \\
\hline $41-50$ & 4 & 33.3 & 6 & 50 & 2 & 16.7 & 12 & & \\
\hline $51-60$ & 2 & 10 & 7 & 35 & 11 & 55 & 20 & & \\
\hline Total & 6 & 15 & 18 & 45 & 16 & 40 & 40 & & \\
\hline
\end{tabular}

There was $55 \%$ of patients with NT pro BNP > 500 in the age category 51-60 years whereas only $16.7 \%$ in this range in the age category 41 to 50 years and again only $8 \%$ in the age category 30 to 40 years. The Majority of 30 to 40 years had NT pro BNP of 100 to $500(62.5 \%)$. In the age category 41 to 50 years, $50 \%$ had NT Pro BNP of
100 to 500 while only $35 \%$ was in this range in the age group of 51-60 years. In the age category of 41 to 50 years, $33.3 \%$ had NT pro BNP of < 100 whereas only $10 \%$ of 51 to 60 years had NT pro BNP of $<100$ and in the age category of 30 to 40 years, no one had NT pro BNP of $<100$. The chi-square test of association is insignificant. 


\section{Gender}

Male Patients $(60 \%)$ were outnumbering the female patients $(40 \%)$.

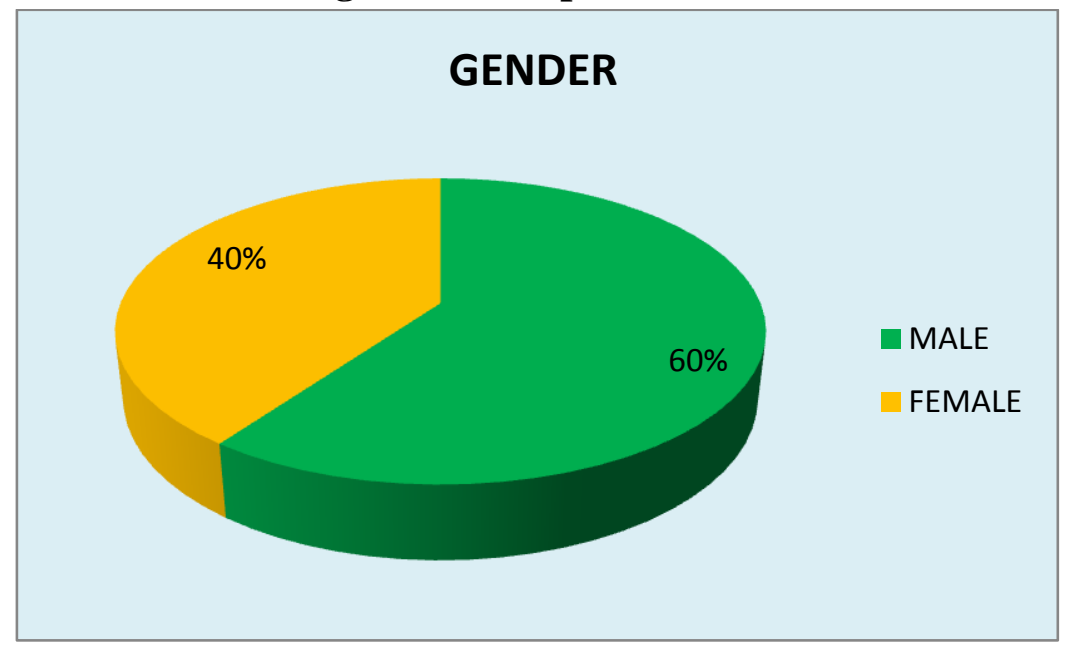

Association of Gender with NT pro BNP

\begin{tabular}{|c|c|c|c|c|c|c|c|c|c|}
\hline \multirow{3}{*}{ Gender } & \multicolumn{6}{|c|}{ NT Pro BNP } & \multirow{3}{*}{ Total } & \multicolumn{2}{|c|}{ Chi-square Test } \\
\hline & \multicolumn{2}{|c|}{$<100$} & \multicolumn{2}{|c|}{$100-500$} & \multicolumn{2}{|c|}{$>500$} & & \multirow{2}{*}{ Value } & \multirow{2}{*}{ 'P' } \\
\hline & $\mathbf{N}$ & $\%$ & $\mathbf{N}$ & $\%$ & $\mathbf{N}$ & $\%$ & & & \\
\hline Male & 2 & 8.3 & 12 & 50 & 10 & 41.7 & 24 & \multirow{3}{*}{2.15} & \multirow{3}{*}{.341} \\
\hline Female & 4 & 25 & 6 & 37.5 & 6 & 37.5 & 1.6 & & \\
\hline Total & 6 & 15 & 18 & 45 & 16 & 40 & 40 & & \\
\hline
\end{tabular}

There were $41.7 \%$ of male with NT-pro BNP $>\quad$ BNP whereas only $2 \%$ of males had NT pro BNP 500 and 37.5 of female with NT pro BNP $>500$. There were $25 \%$ of females with $<100$ NT pro $<100$. The chi-square test of association is insignificant $\left(\mathrm{x}^{2}=2.15, \quad \mathrm{p}=341\right)$.

\section{Cardiac Enzymes (Troponin T/CKMB)}

\begin{tabular}{|l|c|c|}
\hline Troponin T/CKMB & Number & Percentage \\
\hline Normal & 13 & 32.5 \\
\hline Elevated & 27 & 67.5 \\
\hline Total & 40 & 100 \\
\hline
\end{tabular}

Cardiac enzymes was evaluated for all the patients $(\mathrm{N}=27,67.5 \%)$. Cardiac enzymes was normal for $32.5 \%$ of the patients.

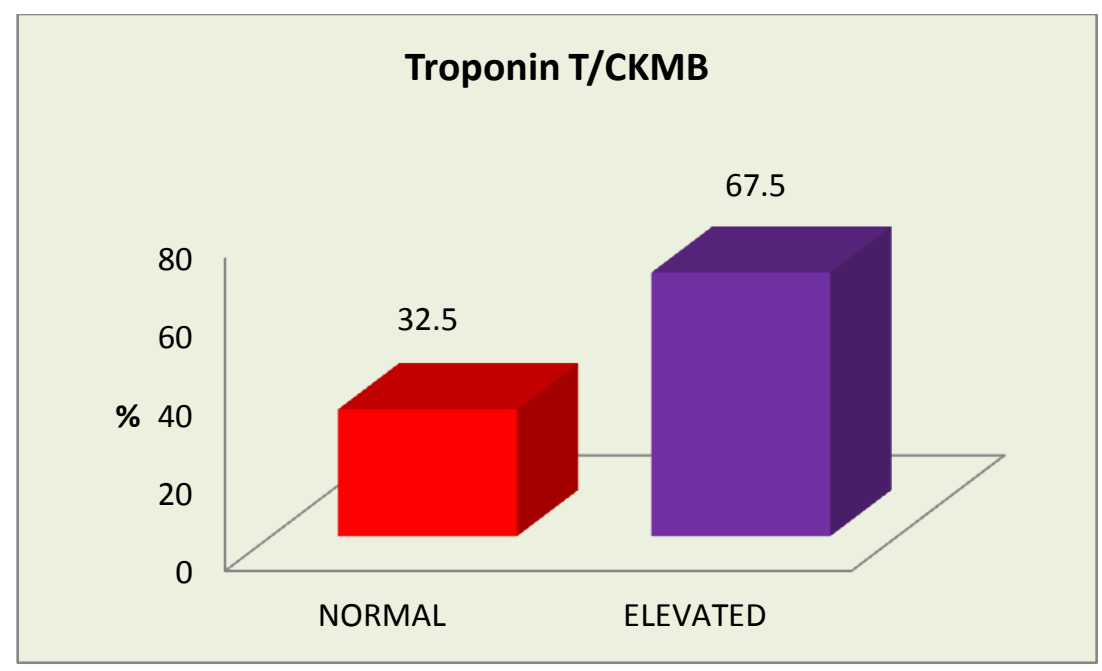




\section{Association of diagnosis, with the NT pro BNP}

\begin{tabular}{|c|c|c|c|c|c|c|c|c|c|}
\hline \multirow{3}{*}{ Diagnosis } & \multicolumn{6}{|c|}{ NT Pro BNP } & \multirow{3}{*}{ Total } & \multicolumn{2}{|c|}{ Chi-square Test } \\
\hline & \multicolumn{2}{|c|}{$<100$} & \multicolumn{2}{|c|}{$100-500$} & \multicolumn{2}{|c|}{$>500$} & & & \\
\hline & $\mathbf{N}$ & $\%$ & $\mathbf{N}$ & $\%$ & $\mathbf{N}$ & $\%$ & & Value & 'P' \\
\hline STEMI & 2 & 8.7 & 10 & 43.5 & 11 & 47.8 & 23 & \multirow{4}{*}{2.54} & \multirow{4}{*}{.64} \\
\hline N STEMI & 2 & 20 & 5 & 50 & 3 & 30 & 10 & & \\
\hline UA & 2 & 28.6 & 3 & 42.9 & 2 & 28.6 & 7 & & \\
\hline Total & 6 & 15 & 18 & 45 & 16 & 40 & 40 & & \\
\hline
\end{tabular}

In STEMI >500 values of NT-Pro BNP was identified for $47.8 \%$ where as in NSTEMI it was only $10 \%$ and in UA it was only $7 \%$ STEMI patients with 100 to $500 \mathrm{NT}$ pro BNP was $43.5 \%$ whereas it was $50 \%$ in NSTEMI and $42.9 \%$ in
UA, In the value of $<100$, only $8.7 \%$ of STEMI was found whereas in NSTIMI 20\% was observed and in UA $28.6 \%$ was observed. The association is statistically insignificant $\left(\mathrm{x}^{2}=2.54, \mathrm{p}=.64\right)$.

\section{Association of LV function with NT pro BNP}

\begin{tabular}{|c|c|c|c|c|c|c|c|c|c|}
\hline \multirow{3}{*}{$\begin{array}{l}\text { LV } \\
\text { Function }\end{array}$} & \multicolumn{6}{|c|}{ NT Pro BNP } & \multirow{3}{*}{ Total } & \multicolumn{2}{|c|}{ Chi-square Test } \\
\hline & \multicolumn{2}{|c|}{$<100$} & \multicolumn{2}{|c|}{ 100-500 } & \multicolumn{2}{|c|}{$>500$} & & V & 6Dי \\
\hline & $\mathbf{N}$ & $\%$ & $\mathbf{N}$ & $\%$ & $\mathbf{N}$ & $\%$ & & value & $P^{\prime}$ \\
\hline Normal & 5 & 62.5 & 1 & 12.5 & 2 & 25 & 8 & \multirow{5}{*}{19.97} & \multirow{5}{*}{.003} \\
\hline Mild & - & - & 7 & 63.6 & 4 & 36.4 & 11 & & \\
\hline Moderate & 1 & 6.7 & 8 & 53.3 & 6 & 40 & 15 & & \\
\hline Severe & - & - & 2 & 33.3 & 4 & 66.7 & 6 & & \\
\hline Total & 6 & 15 & 18 & 45 & 16 & 40 & 40 & & \\
\hline
\end{tabular}

In severe LV dysfunction, $66.7 \%$ had NT pro BNP > 500 whereas $40 \%$ had NT pro BNP > 500 in moderate $\mathrm{v}$ dysfunction. NT pro BNP was greater than 500 for $11 \%$ of mild dysfunction and only $8 \%$ for normal LV function. LV function was normal for majority of patients $(62.5 \%)$ with <
100 NT pro BNP. Only $6.7 \%$ of moderate Lv dysfunction had NT pro BNP $<100$ and no one with severe dysfunction had NT pro BNP $<100$. The chi-square test of association is significant $\left(x^{2}=19.97, p=.003\right)$.

\section{TIMI Score}

\begin{tabular}{|l|c|c|c|c|}
\hline TIMI Score & Number & Percentage & Mean & S.D \\
\cline { 1 - 3 } 1 & 9 & 22.5 & & \\
\cline { 1 - 3 } 2 & 12 & 30.0 & \multirow{3}{*}{2.35} & \multirow{2}{*}{.95} \\
\cline { 1 - 3 } & 15 & 37.5 & & \\
\hline 4 & 4 & 10.0 & & \\
\hline Total & 40 & 100 & & \\
\hline
\end{tabular}

The common IIMS score was 3 and 2 where $37.5 \%$ and $30 \%$ noted respectively. The Mean TIMI score was $2.35 \pm .95$.

TIMI SCORE

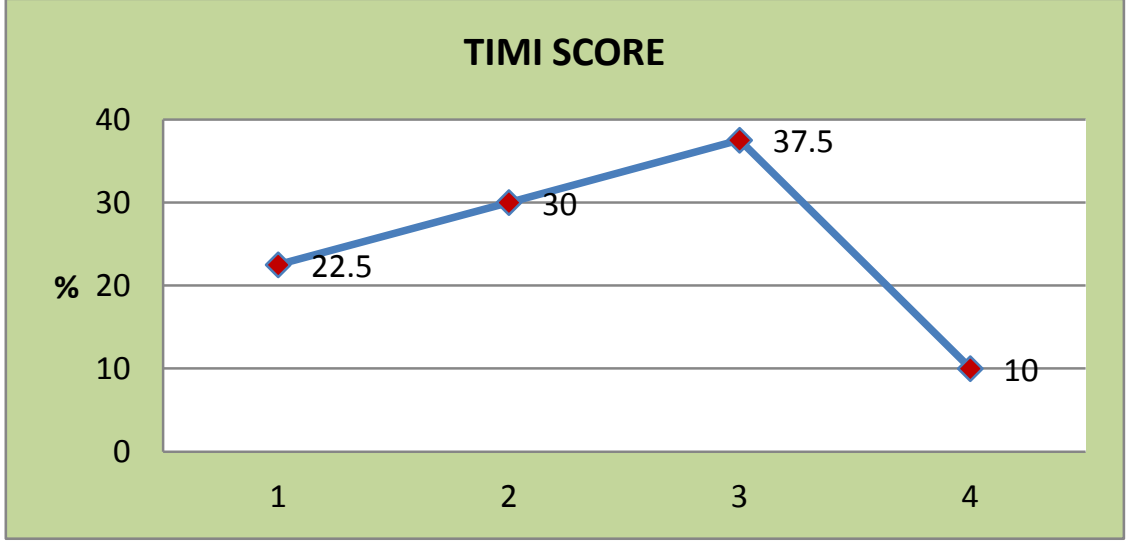


TIMI Score Vs NT pro BNP

\begin{tabular}{|l|c|c|}
\hline & 'r' & 'P' \\
\hline Spearman correlation & 2.54 & .64 \\
\hline
\end{tabular}

The correlation of TIME score with NT pro BNP is peak positive ie if NT pro BNP is higher, TIMI score is also higher \& vice versa but the correlation is insignificant $(\mathrm{r}=2.54, \mathrm{p}=.64)$

\section{Discussion}

The study was conducted includes age group between 30-60 years, the mean age of the patient was 49-10 \pm 7.45 years and males constitutes majority of population around $60 \%$. Majority of patients in age category of 51-60 years (55\%) had NT-pro BNP $>500$. But the association of both age \& sex with NT-pro BNP was statistically insignificant. Among ACS NT-pro BNP was higher $(>100)$ in most of the patients $(85 \%)$ patients in the study .Here in this study majority patients was STEMI (57.5\%) followed by NSTEMI (25\%) \& Unstable Angina (7\%). In several of studies of the patients with acute coronary syndrome, the elevation of Brain natriuretic Peptide NT-pro BNP has been observed. ${ }^{[14-16]}$ There was no significant difference in Troponin T/ CKMB between STEMI \& NSTEMI and normal in case of Unstable Angina.

In Ogawa et al. study shows NT-proBNP was significantly higher in case of STEMI compared with NSTEMI. ${ }^{[17]}$ Like the previous study, our study also had greater value of NT-proBNP in STEMI patients. Even though STEMI patients (47.8\%) had higher value of NT-proBNP >500 than NSTEMI patients (30\%) and UA (28.6\%), the association is insignificant ( $\mathrm{P}$ value 0.64). Conversely in Weber et al. Reported that the highest value of NT- proBNP in NSTEMI group compared to STEMI group ${ }^{[16]}$ here the mean TIMI score is $2.35 \pm 95$, but the correlation between TIMI scoring and NT-proBNP was insignificant.

In Echocardiograpy, LV dysfunction was observed in $80 \%$ of the patients of which $27.5 \%$ had mild LV dysfunction, $37.5 \%$ had moderate dysfunction and $15 \%$ had severe LV dysfunction. In NT-proBNP investigation of dyspnea in emergency department (PRIDE) study the data found to be impressive. ${ }^{[18]}$ in the landmark BNP study, BNP levels $>100 \mathrm{pg} / \mathrm{ml}$ carried an $89 \%$ net present value for excluding heart failure. ${ }^{[19]}$ The majority of patients with severe $L V$ dysfunction (low Ejection Fraction) had greater NT pro BNP $(N=4,66.7 \%)$ and majority of normal $L V$ function(normal Ejection fraction) $(N=5,62.5 \%)$ had lower NT pro BNP $(<100)$. the association is statistically significant. Therefore for patients with more severe LV dysfunction there was significantly higher NT pro BNP (p value .003). The major limitation of the study was the smaller number of subjects. Being a tertiary care center, the majority of the patients admitted were sick with multiple risk factors. So this study had more STEMI patients than NSTEMI or Unstable Angina patients which is not reflecting the incidence pattern of the disease in the general population.

\section{Conclusion}

Our study shows that the NT-pro BNP is reliable biomarker in diagnosing not only STEMI \& NSTEMI but also in unstable angina. NT-pro BNP is high in STEMI than NSTEMI and UA in our study. Even though the study is done for patients without clinical signs of heart failure, the levels of NT-proBNP is significantly had inverse proportion to Ejection Fraction .Hence in future it may be a marker for diagnosis and also for prognosis of Acute Coronary Syndrome. Low NT proBNP levels at the time of admission rule out high-risk patients and patients with heart failure. However, further studies involving large number of patients required to prove the exact correlation between NT-proBNP and patients with Acute Coronary Syndrome.

\section{References}

1. World Health Organisation, Cardiovascular diseases (CVDs), Published on 17 May 2017 http://www.who.int/newsroom/fact-sheets/detail/cardiovasculardiseases-(cvds) 
2. Harrison Principles of internal medicine $19^{\text {th }}$ edition, chapter 294

3. Braunwald $\mathrm{E}$, et al. Unstable angina : diagnosing and management . Rockwille, Md: U.S. Dept.of Health and Human Services, Public Health Agency for Health Care Policy and Research, National Heart, Lung, and Blood Institute, 1994; Clinical practice guideline no.; AHCPR publication no. 94-0602

4. Wagner GS, Marriott HJ. Marriott's Practical electrocardiography. 10th ed. Philadelphia: Lippincott Williams \& Wilkins, 2001:165.

5. Goldberger AL. Clinical electro cardiography: a simplified approach. 6th ed. St. Louis: Mosby, 1999: 81-100.

6. Karras DJ, Kane DL. Serum markers in the emergency department diagnosis of acute myocardial infarction. Emerg Med Clin North Am. 2001;19:321-37.

7. Hamm CW, Goldmann BU, Heeschen C, Kreymann G, Berger J, Meinertz $T$. Emergency room triage of patients with acute chest pain by means of rapid testing for cardiac troponin $\mathrm{T}$ or troponin I. N Engl J Med. 1997;337:1648-53

8. Pope JH, Selker HP. Diagnosis of acute cardiac ischemia. Emerg Med Clin North Am. 2003;21:27-59.

9. Balk EM, Ioannidis JP, Salem D, Chew PW, Lau J. Accuracy of biomarkers to diagnose acute cardiac ischemia in the emergency department: a metaanalysis. Ann Emerg Med. 2001;37:47894

10. Mantymaa P, Vuolteenaho O, Marttila M et al. Atrial stretch in-duces rapid increase in brain natriuretic peptide but not in atrial natriuretic peptide gene expression in vitro. Endocrinology, 1993;133:14701473.

11. Levin ER, Gardner DG, Samson WK.Natriuretic peptides.N Engl J Med, 1998;339:321-328.
12. Bettencourt P, Ferreira A, Pardal- Oliveira $\mathrm{Ne}$ al. Clinical Significance of brain natriuretic peptide in patients with postmyocardial infarction. Clin Cardiol,2000 ;23:921-927.

13. Jernberg T, Stridsberg M, Venge $P$ et al. $\mathrm{N}$-terminal pro brain natriuretic peptide on admission for early risk stratification of patients with chest pain and no ST segment elevation. J Am Coll Cardiol, 2002;40:437-445.

14. Heeschen C, Hamm CW, Mitrovic V.Prognostic value of $B$ type natriuretic peptide in patients with acute coronary syndromes, Eur heart J,2002;23:383.

15. Galvani M,Ottani F, Oltrona L et al.; Italian Working group on Ath reosclerosis, Thrombosis, and Vasucular Biology and the Associazione Nazionale Medici Cardiologi n Ospedalieri (ANMCO). Nterminal pro-brain natriuretic peptide on admission has prognostic value across the whole spectrum of acute coronary syndromes. Circulation ,2004;110:128134.

16. Weber M, Kleine C, Keil E et al.Release pattern of $\mathrm{N}$ - terminal pro $\mathrm{B}$ - type natriuretic peptide (NT-proBNP) in acute coronary syndromes. Clin Res Cardiol,2006;95:270-280.

17. Ogawa A, Seino Y, Yamashita $T$ et al. Difference in elevation of N-terminal proBNP and conventional cardiac markers between patients with ST elevation vs non ST elevation acute coronary syndrome. Circ J,2006; 70:1372-1378.

18. Januzzi J,Camargo C, anwaruddin S.The $\mathrm{N}$-terminal pro-BNP investigation of Dyspnea emergency Department (PRIDE) Study. Am J Cardiol.2005;95:948-954.

19. Mueller C, Scholer A, Laule-Kilian K.Use of B-type natriuetic pepetide in the evaluation and management of acute dyspnea. N Engl J Med .2004;350:647654. 
20. Vladimir Zdravkovic et al. NT-proBNP for prognostic and diagnostic evaluation in patients with acute coronary syndromes, Kardiologia Polska 2013; 71, 5: 472-479; DOI: 10.5603/KP.2013.0093

21. Amulya C. Belagavi et al. Indian Heart J. 2012 May; 64(3): 302-304. 